\title{
PREOCUPAÇÕES ACERCA DA PAISAGEM EM VITÓRIA (ES) - PANORAMA DA PESQUISA E SEUS DESDOBRAMENTOS
}

\author{
THOUGHTS ABOUT LANDSCAPE IN VITÓRIA (ES) - A VIEW OF RESEARCH AND ITS \\ CONSEQUENCES
}

\author{
MENDONÇA, Eneida Maria Souza \\ Arquiteta, doutora em arquitetura e urbanismo pela FAUUSP, professora adjunta do Departamento de \\ Arquitetura e Urbanismo da UFES e pesquisadora do Núcleo de Estudos de Arquitetura e Urbanismo \\ - NAU da UFES. \\ E-mail: eneida@npd.ufes.br
}

\section{RESUMO}

Este artigo busca apresentar determinada experiência no campo da pesquisa acerca da temática relacionada à paisagem urbana, tendo como objeto de estudo a cidade de Vitória. O percurso descrito inicia-se no âmbito da atividade profissional, passando pelo ensino antes de atingir a pesquisa. A problematização é motivada pelo intenso ritmo de urbanização vivenciado pela capital capixaba nas últimas décadas e a conseqüente perda de visibilidade dos referenciais paisagísticos em função do porte das edificações e de sua forma de implantação. A vertente atual alcançada pela pesquisa abrange estudo sobre os espaços públicos, abordando análise qualitativa desses ambientes, bem como a capacidade de agregação social.

Palavras-chave: Paisagem, espaço público, cidadania.

\begin{abstract}
This paper shows an experience of research about urban landscape in Vitória. The described way begins in professional activities, going through the teaching, before arriving in the research area. The quick velocity of urban growth in Vitória and the lost of views of landscape marks because of the size and situation of buildings are the main questions. Now the research is about public space, studying its quality and its capacity of social integration.
\end{abstract}

Key words: Landscape, public space, citizenship.

\section{1 - Introdução}

A experiência aqui exposta evolviu a partir do objetivo de contribuir para orientar a ocupação urbana, tendo como premissa a manutenção dos referenciais da paisagem e como revés a intensidade do processo de urbanização em curso nas cidades brasileiras. Este processo de ocupação acompanhou ao longo do século XX, sobretudo em sua segunda metade, a passagem de um Brasil dito rural para uma situação predominantemente urbana. Diversas cidades de médio e grande porte passaram então, por um ritmo intenso de crescimento, ampliando suas periferias, consolidando contextos de conurbação e assimilando, em localizações selecionadas de seus territórios, processo concentrado de verticalização de construções. Todas estas formas de crescimento ou adensamento além de ampliar as demandas por infra-estrutura de toda a ordem, vem ocorrendo à custa de fortes impactos sociais e ambientais. No âmbito destes últimos, este estudo partiu do interesse de tratar dos impactos sobre a paisagem, enfocando especificamente a gradativa perda das referências paisagísticas, ocasionada pela obstrução da visibilidade destas referências, gerada pela implantação e/ou pelo porte das construções no entorno das mesmas. Um panorama desta pesquisa, de seus desdobramentos, até seu estágio atual, envolvendo a qualidade dos espaços públicos, é o que pretende-se apresentar 
neste artigo. Antes porém, a título de introdução, segue breve relato que ilustra a origem e a trajetória que antecedeu ao estudo em foco.

Mesmo centrada atualmente no campo da pesquisa, esta experiência transpassa ações sobre a cidade, desde a atividade profissional exercida a partir de órgão público, chega à atividade de ensino em curso de arquitetura e urbanismo e fixa-se na investigação científica com ramificações propositivas sobre a realidade urbana mais próxima: o município de Vitória no Espírito Santo e sua região metropolitana. De modo sucinto, procurar-se-á relatar esta passagem.

O olhar sobre a problemática urbana tendo como ponto de vista o órgão público municipal remete a um amplo contexto que envolve dificuldades técnicas e administrativas, bem como a desigual intensidade de pressão política exercida pelos diversos segmentos da sociedade. Neste universo, a constante prevalência da pressão econômica e em particular, imobiliária, indicam arraigadas permanências de um modelo de desenvolvimento impróprio à noção de sustentabilidade. Esta prevalência, ao mesmo tempo que reduz, também desafia a condição técnica dos órgãos públicos. A redução traduz-se, em muitos casos, na limitação das atividades à resolução de demandas pontuais e cotidianas, em detrimento da formulação de análises mais profundas e definições de diretrizes mais abrangente, e também, em detrimento do próprio aperfeiçoamento profissional. O desafio do quadro técnico, por sua vez, ruma para a necessidade de ampliação do potencial de compreensão sobre seu campo de atuação e a identificação de formas mais eficientes de exposição de seu conhecimento e de articulação diante dos demais atores envolvidos, visando atingir qualidades mais significativas nas decisões sobre o urbano.

Considerando a experiência em questão, a aproximação ocorrida quanto às atividades em órgão público, teve como situação mais significativa, a implementação de Plano Diretor Urbano e instituição e coordenação da secretaria executiva de seu conselho. Centrada no município de Vitória em meados da década de 1980, além das características já relatadas, envolvendo limitações técnicas e resultantes político-econômicas, a situação vivenciada relaciona-se a um período de especial expressividade no que se refere ao processo de urbanização local. A região de Vitória correspondia a uma aglomeração urbana em intenso processo de expansão e adensamento, relacionado à consolidação de uma transição econômica da agro-indústria de exportação vinculada à cultura do café para a grande indústria calcada na siderurgia. A atratividade de migrantes para a região de Vitória como conseqüência deste processo resultou tanto na ampliação da classe média, em função da qualificação profissional que a nova atividade requeria, como na ampliação do quadro de pobreza, em função da expectativa de emprego gerada para população sem qualificação profissional. Ressalta-se que ambas as situações contribuíram para alterar consideravelmente a paisagem urbana, seja, no primeiro caso, pela verticalização de construções, seja, no outro, pela ocupação de manguezais.

O ingresso na atividade de ensino, na segunda metade da década de 1980, encontrou um curso de arquitetura e urbanismo que apenas iniciava a formar arquitetos na Universidade Federal do Espírito Santo. A atuação na disciplina de Planejamento Urbano e Regional I, transformada por reforma curricular em Urbanismo I, na década de 1990, foi o veículo que permitiu a realização de ensaios que conduziram à pesquisa. Inicialmente com abordagem em escala geográfica municipal e mais recentemente circunscrita na escala do setor urbano, abrangendo bairro, parte de bairro ou conjunto de bairros, a atividade de ensino experimentada, vem percorrendo a reflexão sobre as normas urbanísticas e seus efeitos sobre a paisagem. $\bigcirc$ estímulo ao enfoque crítico e a busca de soluções alternativas vem sendo a meta neste processo de aprendizagem e de formação profissional, que admite, como desafio ainda inconcluso, a inserção mais incisiva, na experiência de ensino, do ponto de vista do usuário da cidade na percepção e na proposição do ambiente urbano. A atividade de ensino aqui mencionada já foi, em outras oportunidades', amplamente descrita, não cabendo, portanto, detalhá-la. A 
descrição sucinta aqui exposta visa apenas marcar este percurso, próprio, a fim de esclarecer a dimensão da abordagem de pesquisa, objeto deste artigo.

Nesta trajetória, a atuação no campo da pesquisa insere-se como alimentadora da proposição de ensino que se pretende aperfeiçoar e como fonte inovadora articulada à prática profissional. A experiência no âmbito da pesquisa seguiu caminho aproximadamente paralelo ao ensino do urbanismo. Esta abrangeu abordagens do planejamento urbano e regional com enfoque voltado para a região metropolitana de Vitória, seguiu para o estudo quanto à contribuição dos investimentos públicos municipais na ocupação urbana, tratou posteriormente da relação entre as normas urbanísticas e o processo de verticalização de construção em Vitória, para em tempos mais recentes, focalizar a qualidade do ambiente urbano. Esta última abordagem direcionou os trabalhos para o âmbito da paisagem, enfocando o valor de seus referenciais e acreditando na possibilidade de estabelecimento de normas de construção, que os considerem. Uma evolução deste estudo aponta para a análise dos espaços públicos envolvendo a característica urbanística e as formas de apropriação sobre estes empreendidas. É no contexto da pesquisa relacionada à paisagem, que os próximos capítulos se apresentam.

\section{2 - Análise e construção da paisagem}

A pesquisa intitulada Método para análise e construção da paisagem encontra-se atualmente em sua terceira fase. A primeira teve início em 2003-2004, com recursos do Fundo de Apoio à Ciência e Tecnologia da Prefeitura de Vitória. Como resultado daquela pesquisa foi possível estruturar, de modo preliminar, procedimentos metodológicos para análise e construção da paisagem urbana e ensaiar sua aplicação. De forma sintética, estes envolvem: identificação das referências paisagísticas, eleição dos pontos de vista privilegiados, definição dos níveis de percepção desejados, mapeamento da localização e do porte das construções existentes no entorno, estudo para garantia de acessibilidade ao referencial paisagístico, simulação gráfica para determinação de formas futuras de ocupação urbana e proposição de instrumentos urbanísticos que viabilizem a realização da proposta ${ }^{2}$.

O ensaio aplicativo foi desenvolvido em setor urbano de Vitória (ES) de intenso interesse imobiliário, polarizado pela praia do Canto, tendo como foco a manutenção da visibilidade do morro do Guajuru (Figuras 1, 2 e 3). No âmbito da mesma etapa da pesquisa, foram também iniciados os estudos referentes aos instrumentos urbanísticos, buscando no Estatuto da Cidade possibilidades de atuação em benefício da paisagem.

Em uma segunda fase da pesquisa, em 2004-2005, a partir de trabalhos de iniciação científica, tanto o ensaio aplicativo quanto as pesquisas relacionadas ao Estatuto da Cidade, procuram ampliar o campo de análise, testando os procedimentos do método em contexto urbano e sócio-econômico diferenciado do anterior, e estabelecer estudo comparativo. A área objeto de estudo, neste caso, passa a ser a baía noroeste de Vitória, paisagem dominada pela linha aquática, pelo manguezal e pela intensa e densa ocupação por população de baixa renda (Figuras 4 e 5). Nessa ocasião, ainda no âmbito da iniciação cientifica, foram realizadas quatro outras abordagens relacionadas à temática da pesquisa. Uma delas corresponde ao estudo sobre a interferência da publicidade na paisagem urbana, originada na fase anterior da pesquisa. As outras correspondem aos estudos sobre ensino e paisagem, sobre o plano na escala do setor urbano e a paisagem e sobre a evolução da paisagem. $O$ estudo sobre o ensino deseja avaliar a qualificação escolar do cidadão quanto à paisagem. $\bigcirc$ estudo sobre o plano na escala do setor urbano procura investigar a propriedade deste recorte geográfico para as proposições referentes à paisagem. E o estudo sobre a evolução da paisagem, busca experimentar a validade de determinadas fontes, como fotografia e escritos de viajantes, na identificação de elementos significativos da paisagem e respectivas transformações. 

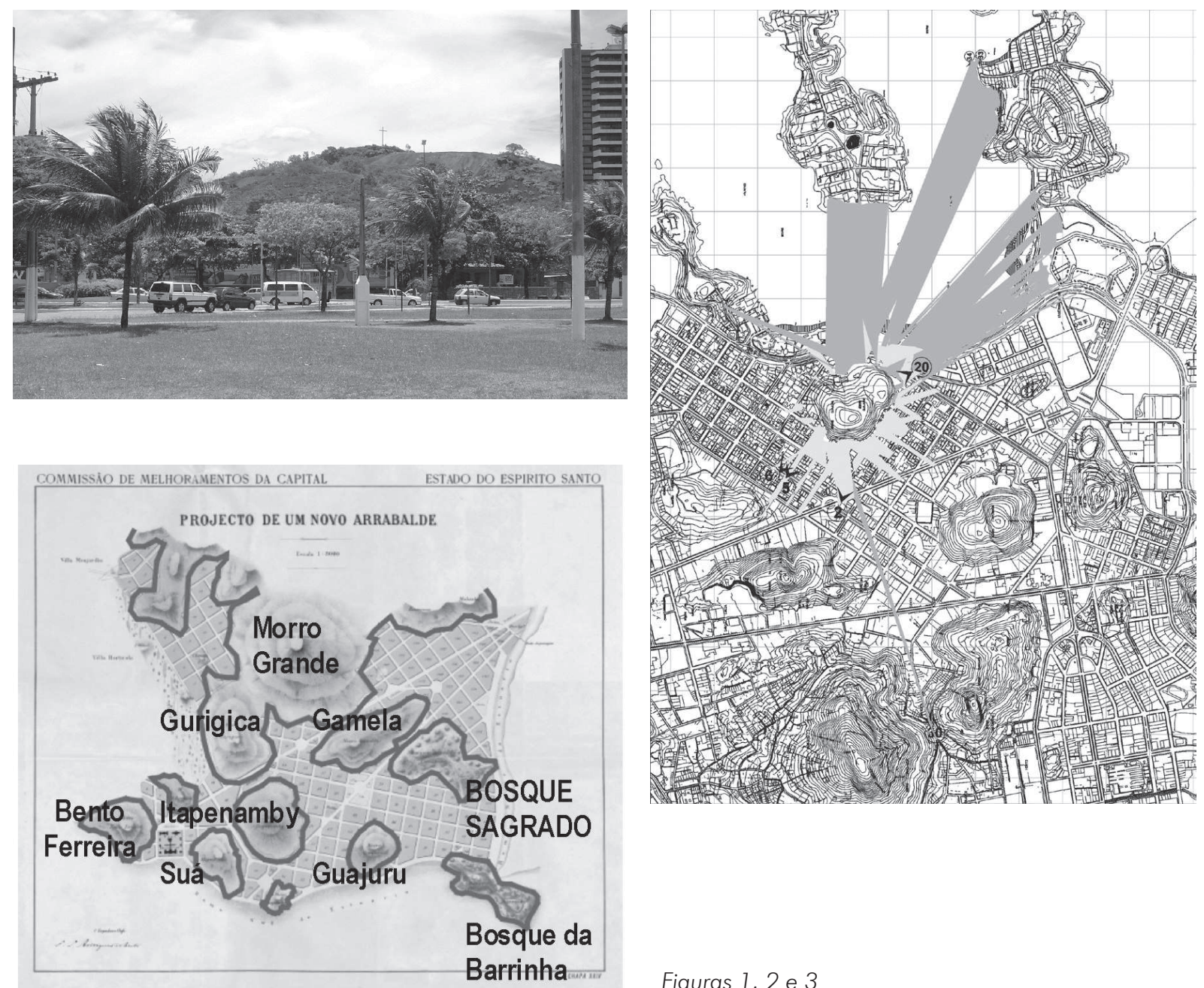

Figuras 1,2 e 3

Diante da amplitude alcançada pela pesquisa julgou-se primordial, em sua terceira fase, 2005 2006, com o apoio do Conselho Nacional de Desenvolvimento Científico e Tecnológico - CNPq, aprofundar conceitos, que permitam dar continuidade à estruturação do método no que diz respeito à análise e construção da paisagem.

Busca-se então, no contexto do projeto de pesquisa atual, realizar estudos teóricos envolvendo dois dos procedimentos metodológicos previstos na fase inicial do estudo: a identificação das referências paisagísticas e a análise dos níveis de percepção da paisagem.

Quanto ao primeiro, a pesquisa realizada apontou o estudo da história referente ao projeto urbanístico e ao processo de urbanização como procedimentos metodológicos de importância na identificação de referenciais paisagísticos valorizados à cada época (Figura 2). Projetos urbanísticos e respectivos memoriais descritivos e/ou justificativos, bem como fotografias, pinturas, cartas de viajantes constituem-se em fontes de destaque para identificação desses referenciais.

Outro procedimento metodológico relevante refere-se aos estudos relacionados aos percursos, auxiliando sobretudo na identificação de referenciais da atualidade. Neste contexto, foram exploradas as cenas seqüenciais de Cullen (1983); os percursos, como um dos cinco elementos urbanos de Lynch (1980) e a abordagem sobre zonas de visualização (Figura 3) desenvolvida a partir da teoria topoceptiva de Kolsdorf (1996). A partir deste entendimento, pretende-se: aprofundar o conhecimento de técnicas para interpretação das fontes citadas e de aplicação dos conceitos até então detectados, bem como identificar outras técnicas e outros referenciais teóricos que auxiliem na identificação de referenciais da paisagem. 

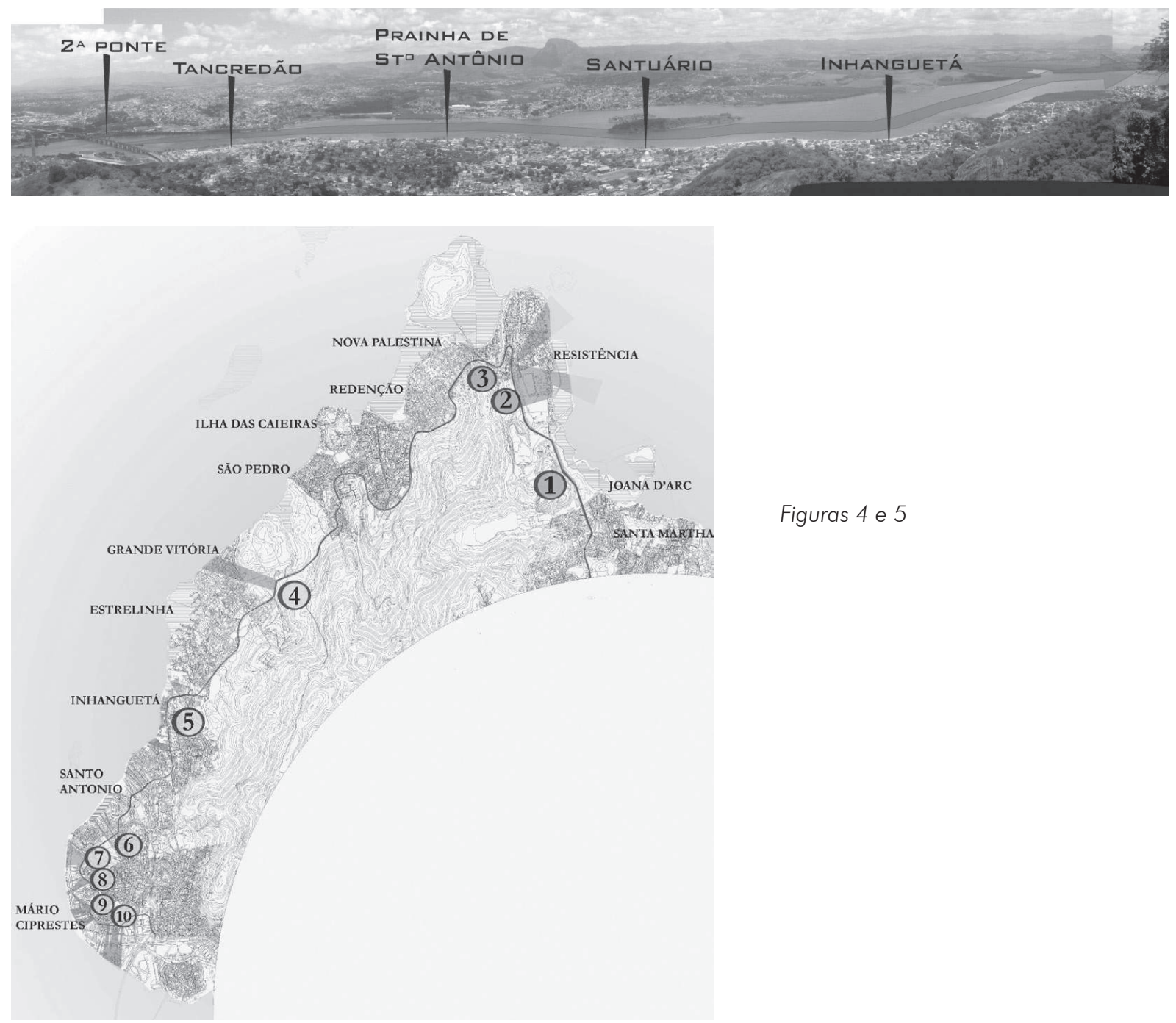

Figuras 4 e 5

Quanto ao segundo procedimento a ser aprofundado e tendo, uma vez mais, como suporte a pesquisa desenvolvida, a análise dos níveis de percepção de determinado elemento paisagístico constitui-se em etapa fundamental para procedimentos seguintes, relacionados à construção da paisagem. A análise dos níveis de percepção deve permitir o reconhecimento e o estabelecimento de valores a serem conservados. Até o momento, com base na mencionada pesquisa, os procedimentos metodológicos desenvolvidos atuam sobre a análise dos níveis de percepção da paisagem a partir de exame e classificação das imagens visualizadas nos diversos pontos de vista referentes ao percurso estabelecido (Figuras de 4 a 10). Alguns conceitos desenvolvidos por Ching (1999) vem auxiliando neste processo.

Neste sentido, pretende-se alcançar o aprofundamento de conceitos que auxiliem o exame e a classificação dos níveis de percepção dos elementos da paisagem, atuando sobre o reconhecimento e o estabelecimento de valores paisagísticos.

A despeito da preocupação fundamental da pesquisa, em sua fase inicial, ter sido o de estabelecer critérios para orientar a ocupação urbana, em consonância com a manutenção da visibilidade dos referenciais da paisagem, ao longo do processo, outras preocupações emergiram. A garantia de acessibilidade e apropriação pública dos espaços relativos a esses elementos referenciais da paisagem, tornaram-se essenciais. Se a preservação dos cones visuais relevantes na paisagem urbana contribui para a orientabilidade do habitante da cidade e reafirma sua identidade diante de seu lugar, a conquista do acesso e uso público dos ambientes de destaque nesta paisagem, contribui para consolidar a cidadania. 
Este entendimento, conduziu a pesquisa ao desdobramento que permitisse examinar e classificar os espaços públicos e suas apropriações.

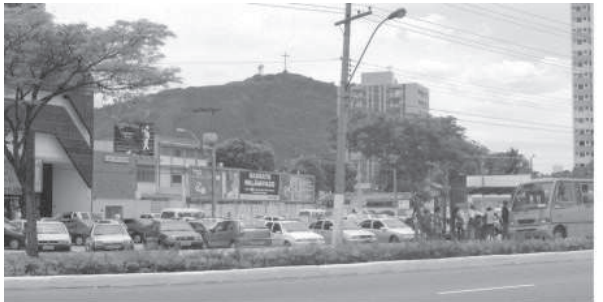

Figura 6: Nível 1

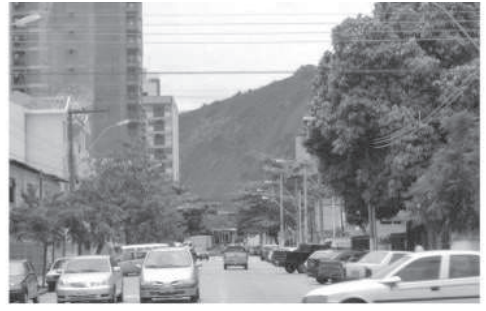

Figura 7: Nível 2

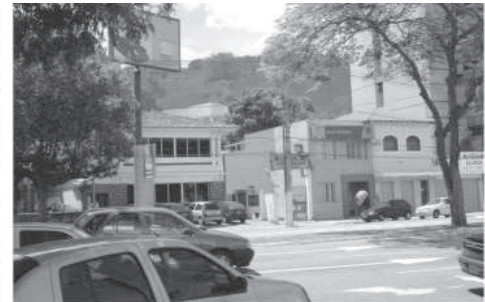

Figura 8: Nível 3

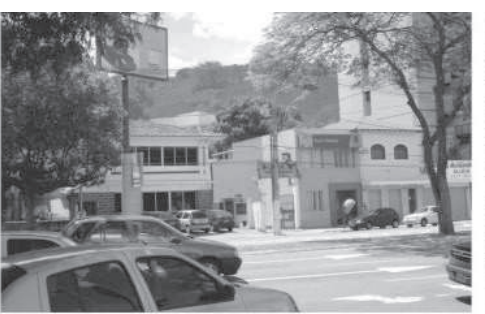

Figura 8: Nível 3

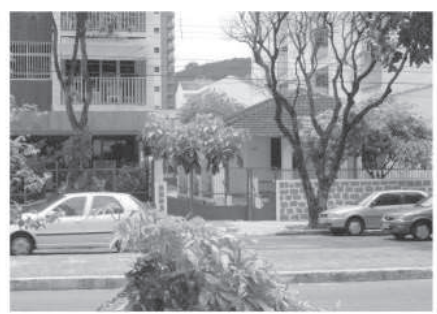

Figura 9: Nível 4

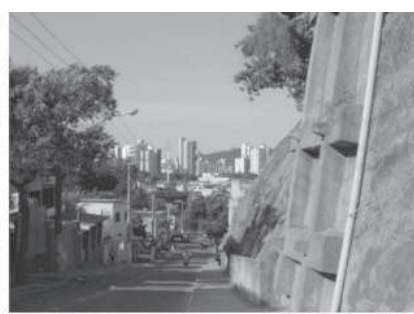

Figura 10: Nível 5

\section{3 - Análise e construção dos espaços públicos}

A pesquisa denominada Análise e construção dos espaços públicos de Vitória - de oeste à leste da ilha, com apoio do Fundo de Apoio à Ciência e Tecnologia da Prefeitura Municipal de Vitória, preocupa-se com as modificações ocorridas ao longo do tempo no âmbito dos espaços públicos e a contribuição destas para as situações de segregação social e perda da noção de identidade do cidadão para com o seu lugar. Além da abordagem histórica, em auxílio à compreensão do contexto atual, a pesquisa apresenta caráter propositivo ao pretender indicar possibilidades de recuperação ou composição de ambientes públicos, entendidos como potenciais elos de agregação social.

A modernização do ambiente urbano, que no século XIX contribuiu para modificar hábitos sociais em importantes cidades européias, atingiu Vitória no início do século XX. Além das melhorias na infra-estrutura em geral, encontram-se no rol dos projetos de modernização da capital capixaba a construção do parque Moscoso (1912), da praça Costa Pereira (1926) e da avenida Jerônimo Monteiro, esta, na categoria de boulevard (PRADO, 2002). Caracterizados também como melhoramentos e embelezamentos, estes projetos transformaram a vida social capixaba, qualificaram o ambiente urbano de seu entorno e elitizaram a apropriação inicial. $O$ passeio no parque, na praça e na avenida tornaram-se programas familiares à alta sociedade local. A popularização do uso destes espaços ocorreu em seguida, fruto da intensificação da atividade portuária e comercial no centro de Vitória. Mesmo percebendo o processo de sucessão de grupos sociais na apropriação dos espaços públicos em Vitória, como foi o caso da prostituição sucedendo a elite no parque Moscoso, até mesmo pela limitada dimensão do ambiente urbanizado da capital, era comum em determinados contextos, a convivência conjunta de grupos distintos. Campos Júnior (1993), ao estudar a construção civil em Vitória, relata, por exemplo, a proximidade social entre construtor e pedreiro, e respectivas famílias, sobretudo filhos, destacando o uso da rua, processo que modificou-se segundo o autor, a partir da construção do edifício, que contribui para separar, segregar. A verticalização de construções em Vitória, iniciada, como processo, na segunda metade da década de 1940, contribuiu para modificar paisagem e relações sociais a partir da década de 1950, ao adquirir maior intensidade construtiva. Embora concentrada de fato no centro, já ocorria, na ocasião, a inserção dos primeiros edifícios na região leste de Vitória, processo que ganhou expressão neste local, a partir da década de 1970. 
A complexificação das relações sociais em Vitória, acompanharam o próprio processo de transformação econômica (da agroexportação para a grande indústria) e de metropolização ocorrido na segunda metade do século XX. Neste contexto a década de 1970 representa momento de inflexão significativo. A ampliação da classe média propiciada por novos empregos nas grandes empresas em instalação e a concomitante ampliação da população de menor renda excedente no mercado formal de trabalho, constituem as referências imediatas para entendimento do quadro de segregação social vigente. É neste contexto que iniciou-se na mesma década de 1970 a ocupação dos mangues na região oeste-noroeste de Vitória.

Inserida no mercado global, no pleno desempenho de sua função portuária e industrial-siderúrgica, Vitória apresenta processos sociais complexos, como os vividos nas principais cidades brasileiras. Sem ignorar essa complexidade e ao mesmo tempo reconhecendo a impossibilidade de abranger todas as suas facetas, esta pesquisa valoriza o espaço público como elemento potencialmente aglutinador das funções sociais e do exercício da cidadania. Neste sentido, analisar o espaço público em Vitória, entendido a princípio como rua, praça e parque, considerando suas características físicas e as formas de apropriação subjacentes, significa, no contexto deste estudo, entender melhor as potencialidades do lugar, o afeto de seu povo por este mesmo lugar e as dificuldades de convívio social subjacentes.

A escolha de duas regiões de contexto sócio econômico diferenciado visa permitir rico estudo comparativo e despertar para a situação de injustiça social presente. Assim, as áreas objeto de estudo são as mesmas já indicadas e adotadas nos estudos anteriores e encontram-se opostas em localização, condição sócio-econômica e característica urbanística. No entanto, ambas passaram, e de certo modo, ainda vivenciam, intenso ritmo de urbanização com conseqüências para a conformação de seus espaços públicos. Tratam-se da região conhecida como baía noroeste de Vitória, polarizada pelo bairro São Pedro e a região à leste-nordeste da ilha polarizada pelo bairro praia do Canto. A região de São Pedro, abrigando população de baixa renda, sofreu acelerado processo de ocupação em aterro de lixo sobre mangue, a partir de meados da década de 1970. A região da praia do Canto, abrigando população de alta renda e características de novo centro, sofreu, na mesma ocasião, processo intensivo de verticalização de construções. A despeito dos contrastes, ambas representam o processo de desenvolvimento assumido pelo Espírito Santo ao longo da segunda metade do século XX, que gerou êxodo rural pela crise na cultura cafeeira (década de 1960) e atratividade industrial com a implantação dos grandes projetos (década de 1970). A intenção de abordar a temática aqui lançada de oeste à leste da ilha de Vitória sugere desde já a construção de um primeiro elo composto de fato pela continuidade física destas regiões (a nordeste).

Em auxílio a abordagem que remete às assimetrias sociais, busca-se apoio em Foucault (1993), Bourdieu (2001) e Caldeira (1996). A abordagem sobre o meio urbano, sua morfologia e complexidade encontra referência em Santos (1985), Lamas (s/d), Arantes (1998), Carlos (2001) e Souza (2002). Santos (1981) e Da Matta (1997) constituem-se em reforço antropológico fundamental à compreensão do uso da rua. Culen (1993) e Lynch (1980) permanecem referências quanto ao enfoque urbanístico e paisagístico. Sobre os aspectos relacionados à classificação de espaços públicos as referências são Macedo (1999) e Carneiro (2000).

Sendo este o atual estágio do panorama aqui apresentado, vale ainda assinalar, na pesquisa, a previsão de atividade interativa com as lideranças comunitárias. Prevista inicialmente em forma de seminários, esta encontra-se atualmente programada, de fato, em forma de curso, seguindo o interesse demandado pelas associações de bairro. A programação compreende a transmissão de informações conceituais, históricas e técnicas sobre o espaço público pela equipe de pesquisadores e a realização de exercícios de reflexão sobre a realidade local, buscando com os líderes comunitários, avançar no desejo de inserir o usuário da cidade no processo de conhecimento e realização. 


\section{Notas}

(1) Trata-se de experiência apresentada no Seminário Internacional Psicologia e Projeto do Ambiente Construído: Interface e Possibilidades em Pesquisa e Aplicações, no Rio de Janeiro, UFRJ, em 2000, e publicada em artigo: MENDONÇA, Eneida Maria Souza. A percepção ambiental na introdução ao estudo do espaço urbano: registro, análise e projeto. In: Projeto do lugar - Colaboração entre psicologia, arquitetura e urbanismo. Rio de Janeiro: Contra capa Livraria Ltda., 2002. Vale indicar complementação da experiência no Fórum de Debates Ambiente Urbano, Indivíduo e Sociedade: Fundamentos e Experiências, em Vitória, UFES, em 2003.

(2) Os resultados da pesquisa foram expostos em relatório, além de apresentados e publicados de modo sintético em MENDONÇA, Eneida Maria Souza. Instrumentos para ocupação urbana em favor dos referenciais da paisagem in Anais do Encontro Nacional da ANPUR, Salvador, UFBA, 2005.

\section{Bibliografia}

ARANTES, Otília Beatriz Fiori. Urbanismo em fim de linha e outros estudos sobre o colapso da modernização arquitetônica. São Paulo: Edusp, 1998.

BOURDIEU, Pierre (Coord.). A miséria do mundo. Petrópolis: Vozes, 2001.

CALDEIRA, Tereza. A cidade fortificada. Folha de São Paulo, 22 jun. 1996.

CAMPOS JÚNIOR, Carlos Teixeira. O Capitalismo se apropria do espaço: A construção civil em Vitória (ES). 1993. Tese (Doutorado) - Faculdade de Arquitetura e Urbanismo, Universidade de São Paulo, São Paulo, 1993.

CARLOS, Ana Fani Alessandri. Espaço-tempo na metrópole: A fragmentação da vida cotidiana. São Paulo: Contexto, 2001.

CARNEIRO, Ana Rita Sá; MESQUITA, Liana de Barros. Espaços livres do Recife. Recife: Prefeitura da Cidade do Recife/ Universidade Federal de Pernambuco, 2000.

CHING, Francis D. K. Arquitetura, forma, espaço e ordem. São Paulo: Martins Fontes, 1999.

CULEN, Gordon. Paisagem urbana. São Paulo: Martins Fontes, 1983.

DA MATTA, Roberto. A casa \& a rua: Espaço, cidadania, mulher e morte no Brasil. 5 ed. Rio de Janeiro: Rocco, 1997.

FOUCAULT, Michel. Vigiar e punir. Petrópolis: Vozes, 1993.

KOLSDORF, Maria Elaine. A apreensão da forma da cidade. Brasília: Editora Universidade de Brasília, 1996.

LAMAS, José M. Ressano Garcia. Morfologia urbana e desenho da cidade. Fundação Calouste Gulbenkian e Junta Nacional de Investigação Científica e Tecnológica, s/d.

LYNCH, Kevin. A imagem da cidade. São Paulo: Martins Fontes, 1980.

MACEDO, Silvio Soares. Quadro do paisagismo no Brasil. São Paulo: Edusp, 1999 (Coleção Quapá).

MENDONÇA, Eneida Maria Souza. Instrumentos para ocupação urbana em favor dos referenciais da paisagem. In: ENCONTRO NACIONAL DA ANPUR, 2005, Salvador. Anais... Salvador: UFBA, 2005.

PORTEOUS, J. Douglas. Environmental aesthetics. Ideas, politics and planning. Londres/Nova York: Routledge, 1996.

PRADO, Michele Monteiro. A modernidade e seu retrato. 2002. Dissertação (Mestrado) - Universidade Federal da Bahia, Salvador, 2002.

SANTOS, Milton. Espaço e método. São Paulo: Studio Nobel, 1985.

SOUZA, Marcelo Lopes de. Mudar a cidade: Uma introdução crítica ao planejamento e à gestão urbanos. Rio de Janeiro: Bertrand Brasil, 2002.

TUAN, Y Fu. Topofilia. São Paulo: Difel, 1980. 